\title{
USO DA IOT, BIG DATA E INTELIGÊNCIA ARTIFICIAL NAS CAPACIDADES DINÂMICAS
}

\author{
USE OF IOT, BIG DATA AND ARTIFICIAL INTELLIGENCE IN DYNAMIC CAPABILITIES
}

\section{Cláudio Márcio Campos Mendonça}

cmarcio@gmail.com

Universidade Federal do Amapá (UNIFAP), Macapá/AP, BRASIL

\section{António Manuel Valente de Andrade}

aandrade@porto.ucp.pt

Universidade Católica Portuguesa (Católica Porto Business School), Porto, PORTUGAL

\section{Manoel Veras de Sousa Neto}

manoel.veras@uol.com.br

Universidade Federal do Rio Grande do Norte (UFRN), Natal/RN, BRASIL

\section{Resumo}

O objetivo do artigo foi descrever a utilização e importância de elementos da transformação digital (IoT, Big Data e Inteligência Artificial) como apoio aos processos das capacidades dinâmicas em organizações de uma capital brasileira. A pesquisa caracterizou-se como exploratória e descritiva, com abordagem quantitativa. Foram selecionados 53 questionários de gestores de negócio e TI. Foi identificado que, na percepção de gestores de negócio e de TI, os elementos da transformação digital, mesmo com a utilização relativamente baixa, principalmente da IoT e IA, e com melhor destaque para Big Data, são avaliadas com importância, seja nos dias atuais, bem como, na perspectiva até 2025, nos processos que envolvem as capacidades dinâmicas de analisar o ambiente (Sensing), aproveitar as oportunidades (Seizing) e gerir as ameaças e transformações (Managing Threats/Transforming). Com maior destaque do Big Data nos processos da capacidade dinâmica de aproveitar as oportunidades.

Palavras-chave: Transformação Digital. Capacidades Dinâmicas. Internet das coisas. Big Data. Inteligência artificial.

\section{Abstract}

The objective of the article was to describe the use and importance of elements of digital transformation (IoT, Big Data and Artificial Intelligence) as support for processes of dynamic capabilities in organizations of a Brazilian capital. A research is characterized as exploratory and descriptive, with a quantitative approach. 53 questionnaires were selected from business managers and IT managers. It has been identified that in the perception of business and IT managers the elements of digital transformation, even with relatively low information, mainly from IoT and IA, with a better focus on Big Data, are evaluated with importance, both nowadays, as well as in practice, up to 2025, in processes involving the dynamic capabilities of analyzing the environment (Sensing), seiring opportunities and managing as threats and transformations (Managing Threats / Transforming). With greater emphasis on Big Data in the processes of the dynamic ability to seize as opportunities.

Keywords: Digital Transformation. Dynamic Capabilities. Internet of Things. Big Data. Artificial Intelligence. 


\section{Introdução}

A Tecnologia da Informação (TI) é vista hoje como uma função cada vez mais indispensável na busca pela efetividade. Para Weill e Ross (2006) a influência da TI no desempenho empresarial continuará a crescer, quer seja na empresa que se concentra na eficiência, na inovação, no crescimento, na responsabilidade dos clientes, quer seja na integração dos negócios. E que a TI deve ser compreendida de forma ampla e com uma abrangência das mais variadas formas de investimento de uma organização, com o intuito de agregar valor com a utilização de recursos tecnológicos.

A adoção de novos recursos tecnológicos levanta questões de riscos, que de acordo com Veras (2012), necessitam que questionamentos sejam feitos, principalmente sobre a utilização da TI e sua relação com o negócio. Para o autor, se processos de negócio são modificados em detrimento de estratégias que se alteram com uma constância, devido principalmente as mudanças do ambiente organizacional (fatores internos e externos), por que não ter uma TI flexível que permita a rápida reconfiguração da organização? Será que a TI permite uma flexibilidade das organizações ou existe um "engessamento" ocasionado pelos processos de TI?

A TI é elemento relevante a partir da $3^{a}$ revolução industrial, nos dias atuais a indústria é elemento de uma economia que gera bens materiais, normalmente, altamente mecanizada e automatizada. Desde o início da industrialização, alguns avanços tecnológicos levaram as rupturas denominadas "revoluções industriais". Atualmente, segundo alguns autores, estamos passando por outra quebra de paradigma, através da denominada quarta revolução industrial.

Nos últimos anos a economia vem passando, em alta velocidade, por um processo de transformação, onde a matriz impulsionadora é basicamente formada por inovações avançadas nas áreas: digital, material e biológica. Essa aceleração é originada da convergência de avanços em tecnologias emergentes, tais como: computação em nuvem, internet das coisas (IoT), robótica, inteligência artificial, veículos autônomos, impressão 3D, nanotecnologia, biologia sintética, biomimética, armazenamento de energia dentre outros (Nobre et al., 2016; Preuveneers \& Ilie-Zudor, 2017; Schwab, 2016).

A quarta revolução industrial, de forma mais ampla, possui tecnologias divididas nas categorias: física, digital e biológica (Schwab, 2016). Da categoria digital, destacam-se a computação em nuvem, IoT, Inteligência Artificial e Big Data, que fazem parte da denominada Transformação Digital, que é uma perspectiva de uso da tecnologia da informação e da comunicação (TIC), onde ela vem a atuar como elemento preponderante na transformação e reconfiguração de elementos organizacionais, tais como: estratégia, processos, cultura e estruturas (Hess, Benlian, Matt, \& Wiesböck, 2016).

Além dessa transformação digital, as organizações necessitam ter capacidades de se reconfigurarem frente a um mercado tão competitivo. Essas Capacidades Dinâmicas (CD) ou Dynamic Capabilities, vêm sendo observadas como um acontecimento nas organizações e despertando interesse no ambiente acadêmico, bem como no corporativo nos seus mais diversos segmentos. As CDs permitem as organizações sentirem e moldarem oportunidades e ameaças; aproveitarem oportunidades e manterem a competitividade através do aprimoramento, combinação, proteção, reconfiguração dos ativos intangíveis e tangíveis.

Frente a esses dois elementos, a transformação digital e as capacidades dinâmicas, o presente artigo levanta o questionamento sobre como está a utilização de tecnologias da transformação digital (IoT, Big Data e IA) nos processos de capacidades dinâmicas em empresas Brasileiras? Diante da problemática, o seguinte objetivo foi definido para o presente artigo, que é o de descrever a utilização e importância de elementos da transformação digital (IoT, Big Data e IA) como apoio aos processos das capacidades dinâmicas em organizações de uma capital brasileira.

O artigo é composto pelo referencial teórico que aborda as questões relacionadas a transformação digital e suas tecnologias (IoT, Big Data e IA) e as capacidades dinâmicas. A metodologia definida para se alcançar o objetivo proposto. Além da análise e interpretação dos resultados e considerações.

\section{Referencial Teórico}

\section{Quarta Revolução Industrial e Transformação Digital}

A temática da quarta revolução industrial vem ganhando espaço nas publicações científicas, desde que a terminologia "Industry 4.0" foi utilizada de forma mais marcante em 2011, na Feira de 
Hannover (Alemanha), através de uma associação de representantes de negócios, política e academia, que tinha como objetivo fortalecer a competitividade da indústria Alemã (Hermann, Pentek, \& Otto, 2015; Schwab, 2016).

Conceitualmente, para Schwab (2016), o modelo produtivo anterior está em processo de ruptura, e que a quarta revolução industrial ou simplesmente indústria 4.0, é o elemento que vem gerando esse processo de forma rápida. A quarta revolução industrial, trata-se na sua essência da fusão de tecnologias como: sistemas e máquinas inteligentes e conectadas; nanotecnologia; energias renováveis; e computação quântica, e a interação entre os domínios físicos, digitais e biológicos. Essa integração entre sistemas físicos e virtuais de fabricação com a criação das fábricas inteligentes, fazem com que a quarta revolução industrial possibilite a total personalização de produtos e a criação de novos modelos operacionais.

Outra característica que torna o tema mais interessante, é que pela primeira vez uma revolução é prevista a priori, antes de acontecer, e não após o fato (Hermann et al., 2015). Para Schwab (2016) essa revolução pode ser detectada como essas tecnologias vêm ganhando espaço, com velocidade (ritmo exponencial e não linear), amplitude e profundidade (combinação de várias tecnologias) eimpacto sistêmico (transformações em sistemas inteiros). A indústria 4.0 prevê ambientes inteligentes industriais intensivos em conhecimento, onde os produtos inteligentes personalizados são criados através de processos e procedimentos inteligentes (Preuveneers \& IlieZudor, 2017). Os autores Oesterreich \& Teuteberg (2016) e Pfohl, Yahsi, \& Kurnaz (2015), afirmam que hoje em dia, a ideia visionária da Indústria 4.0 possui outros sinônimos como fabricação inteligente, produção inteligente ou internet industrial.

A quarta revolução de forma mais ampla, possui tecnologias impulsionadoras e categorizadas em: física, formada por veículos autônomos, impressão em 3D, robótica avançada e novos materiais; a digital, com elementos como a computação em nuvem, internet das coisas (Io'T) e a inteligência artificial; e por último a biológica, composta pela biologia sintética e engenharia genética (Schwab, 2016).

Da categoria digital, alguns elementos como a computação em nuvem, IoT, Inteligência Artificial e Big Data, fazem parte da denominada Transformação Digital, que é uma perspectiva de uso da tecnologia da informação e da comunicação (TIC), onde ela vem a atuar como elemento preponderante na transformação e reconfiguração de elementos organizacionais, tais como: estratégia, processos, cultura e estruturas (Hess et al., 2016).

De forma mais específica, essa transformação se dá através de tecnologias como computação em nuvem, redes sociais, acesso com telefonia móvel, analíticos (Big Data), além de mecanismo de inteligência artificial (Hess et al., 2016; Kane, Palmer, Philips Nguyen, Kiron, \& Buckley, 2015; Singh \& Hess, 2017).

Conforme argumentam Kane etal. (2015), a capacidade de reinventar digitalmente o negócio é determinada em grande parte por uma estratégia digital clara, apoiada por líderes que promovem uma cultura capaz de mudar e inventar o novo. Embora essas ideias sejam consistentes com as evoluções tecnológicas anteriores, o que é relevante para a transformação digital é que a tomada de decisão sobre riscos, está se tornando uma cultura mais aceita à medida que mais empresas digitalmente avançadas buscam novos níveis de vantagem competitiva, através da inovação e introdução dessas tecnologias.

De acordo com Hess et al. (2016) e Singh \& Hess (2017), a transformação digital está direcionada com as mudanças que as tecnologias digitais podem trazer no modelo de negócios de uma empresa, o que resulta em alteração de produtos ou estruturas organizacionais ou na automação de processos, ou seja, reconfiguração dos ativos da organização.

$\mathrm{Na}$ transformação digital a perspectiva da gestão da informação e do conhecimento, a inserção de tecnologias que tratam da geração de dados, como a Internet das Coisas (Io'T), bem como ferramentas que lidam com o tratamento da exploração desses dados (analytics - Big Data), tais como: inteligência artificial, geoanálise e a computação cognitiva. Esses elementos estão passando por um processo de aceleração sem precedentes (Francisco, Kugler, \& Larieira, 2017). Hoje, os mais diversos setores da economia vêm passando por um processo de transformação, a estrutura de custos vem sofrendo impactos diretos de várias tecnologias, como robotização, drones, impressão em três dimensões (3D), blockchain, nanotecnologia, criptomoedas, entre outras (Francisco et al., 2017).

As empresas estão atravessando o processo de transformação digital e para Kane et al. (2015), as organizações estão criando habilidades para buscar a 
maturidade digital, e as que conseguem amadurecer digitalmente são quatro vezes mais propensas a fornecer aos colaboradores as habilidades necessárias para esse amadurecimento digital.

A transformação digital deve passar, necessariamente, pela definição da estratégia para essa transformação. Hess et al. (2016) afirmam que essa agenda digital deve ser alinhada com outras estratégias operacionais ou funcionais, podendo atuar como um conceito unificador para integrar todos os esforços de coordenação, priorização e implementação da transformação digital em uma organização.

\section{IoT - Computação em Nuvem e Internet das Coisas}

A internet vem mostrando sua contribuição com o ambiente organizacional, e uma tendência cada vez mais presente nas empresas é a adoção de soluções de computação em nuvem $(\mathrm{CN})$. A CN tornou-se um componente essencial para implementação de estratégias na qual a área de TI é demandada (Santos, Amelotti, \& Villar, 2012).

A computação em nuvem apresenta o conceito de uma computação utilitária, porque é possível fazer provisão de recursos computacionais que são medidos e cobrados pelo uso, assim como serviços cotidianos como água, energia, etc (Aleem \& Ryan Sprott, 2012). Marston, Li, Bandyopadhyay, Zhang, \& Ghalsasi (2011) comparam a computação em nuvem com o forte e fácil acesso à energia elétrica.

A computação em nuvem, na sua conceituação, tem alguns aspectos em comum abordados por vários autores, como: a redução de custo, a padronização dos serviços de TI, a maior facilidade de mensuração, o pagamento somente do que realmente se utilizou, acesso a inovação, disponibilidade imediata de recursos e a escalabilidade. Além de fatores como: confiabilidade, escalabilidade, economia, privacidade e segurança (Badger, Patt-corner, \& Voas, 2011; Lui et al., 2011; Marston et al., 2011; Mell \& Grance, 2010; Veras, 2012).

Diante dessa tecnologia e da sua junção com tecnologias como sistemas embarcados, microeletrônica, comunicação e sensores, surge o conceito de Internet das Coisas, oriunda do inglês Internet of Things (IoT). Termo utilizando primeiramente por Ashton (2009) ao trabalhar com conceito de RFID (Radio Frequency Identification). Embora hoje em dia a definição tem sido mais abrangente, engloba uma gama de aplicações, como serviços de saúde, serviços públicos, transporte, etc (Gubbi, Buyya, Marusic, \& Palaniswami, 2013). Além de ser considerada a nova onda tecnológica e econômica (Mukherjee et al., 2017).

A IoT é uma inovação tecnológica que trouxe inteligência aos objetos, ou como afirmam Zhu, Leung, Shu, \& Ngai (2015), é um facilitador inteligente do mundo, que tem na sua estrutura, artefatos como a Internet e objetos inteligentes (Galegale, Siqueira, Souza, \& Silva, 2016). As tecnologias de identificação de rádio frequência (RFID) e de sensores, evoluirão ainda mais para enfrentar este novo desafio no qual os sistemas de informação e comunicação estão invisivelmente integrados no ambiente ao nosso redor (Gubbi et al., 2013).

Já Van Kranenburg \& Anzelmo (2008) percebem que a IoT surge como uma inovação tecnológica que vem trazendo grandes mudanças para o gestão da cadeira de suprimentos. Onde o objetivo é conectar vários objetos (por exemplo, telefones celulares, computadores, carros, eletrodomésticos, sensores RFID) com endereços exclusivos, para que possam interagir um com o outro, e também com o mundo (Dinh, Kim, \& Lee, 2017; Gubbi et al., 2013; Zhu et al., 2015). Além de fornece a infraestrutura necessária para acessar de forma transparente sensores e processos usando protocolos padronizados independentemente de hardware, sistemas operacionais ou localização (Hart \& Martinez, 2015).

A detecção ubíqua permitida pelas tecnologias da rede de sensores sem fio (Wireless Sensor Network - WSN), perpassa várias áreas da vida moderna e permite a capacidade de medir, inferir e compreender indicadores ambientais, desde delicados indicadores ecológicos (recursos naturais) até ambientes urbanos. O desenvolvimento da IoT é um complexo processo de inovação tecnológica em larga escala que envolve vários elementos (Mukherjee et al., 2017).

Hoje várias pesquisas buscam definir campos de atuação da IoT, e surgem várias aplicações em áreas diferentes, tais como: indústria; agricultura; logística/ cadeira de suprimentos; transporte; proteção ambiental; segurança pública e privada; medicina, casa inteligente, energia e construção civil (Chan, 2015; Dijkman, Sprenkels, Peeters, \& Janssen, 2015; Gubbi et al., 2013; Mukherjee et al., 2017). A IoT é uma tecnologia emergente capaz de influenciar o surgimento de novas capacidades nas organizações, fornecendo novos dados e os recursos computacionais necessários para a criação de aplicativos revolucionários e tornando a Io'T mais operacional. 


\section{Inteligência Artificial (IA)}

Nos últimos anos, há visivelmente uma evolução dos artefatos tecnológicos que circundam a sociedade nas suas mais variadas perspectivas, para Makridakis (2017) um desses artefatos é a IA, e ele afirma que o impacto das revoluções industrial e digital ou da informação, afetou substancialmente a sociedade, mas há uma nova revolução sendo formada pela Inteligência Artificial(IA) e que gerará forte impacto nas empresas e empregos. As pessoas poderão comprar bens e obter serviços de qualquer lugar do mundo usando a Internet e explorar os benefícios ilimitados da IA, pois computadores e os robôs provavelmente se aproximarão da inteligência humana nos próximos 20 anos.

A IA está presente no dia-a-dia das pessoas e empresas, um exemplo disso são recursos de reconhecimento de voz, de face e sugestões de escrita disponíveis nos smartphone de hoje (Makridakis, 2017). Com essa popularização é possível afirmar que a IA se encontra em novo estágio evolutivo, e que alguns denominam de IA 2.0 (Pan, 2016).

A IA é um vasto campo de pesquisa, tendo várias abordagens diferentes, dentre elas: a teoria fuzzy; árvores de decisão; e redes neurais. Vêm sendo utilizadas em vários tipos de aplicações em áreas diferentes (Costa, 2006; Klashanov, 2016; Kornienko, Kornienko, Fofanov, \& Chubik, 2015; Wolfert, Ge, Verdouw, \& Bogaardt, 2017). E essas abordagens basicamente têm como foco ensinar os computadores a pensar por si mesmos e a improvisar soluções para problemas comuns, dessa forma a IA não somente aplica decisões pré-programadas, mas sim, exibe algumas capacidades de aprendizado (Makridakis, 2017).

De acordo com Pan (2016) a integração da IA com demandas industriais forçou mudanças significativas como os serviços são prestados. O autor cita alguns exemplos: $\mathrm{O}$ robô de bate-papo Xiaobing, desenvolvido pela Microsoft, orienta a transformação de uma interface gráfica tradicional para uma interface interativa com entendimento natural e emocional. Também ainda a Microsoft, adquiriu a rede social LinkedIn e vem preparando para reconstruir a comunidade usando a tecnologia IA. Além disso, o sistema Watson desenvolvido pela IBM foi utilizado de forma operacional nos hospitais, com o objetivo de detectar dentre milhões de registros de pacientes, alternativas de diagnóstico de câncer e a Baidu sendo utilizada para traduções automáticas, linguagem natural e veículos inteligentes.
Algumas novas tecnologias de IA estão se fortalecendo e emergindo, são elas: Big Data baseado em IA (transformação de big data em conhecimento); Internet Crowd Intelligence (usando para trabalhar com alocação de tarefas, fluxos de trabalho complexos e ecossistemas de resolução de problemas); Crossmedia Intelligence (uma característica importante da inteligência humana envolve a utilização abrangente de informações obtidas de várias formas de percepção, incluindo visão, linguagem e senso auditivo, para permitir reconhecimento, inferência, design, criação e previsão); Human-machine hybrid-augmented intelligence (são sistemas de inteligência híbrida são formados pela cooperação entre computador e humanos, de modo a formar uma inteligência aumentada); e Autonomous-intelligent systems que trata do desenvolvimento de robôs autônomos e veículos autônomos (Dresner \& Stone, 2008; Pan, 2016).

De acordo com Schwab (2016), a inteligência artificial e a robótica, gerarão uma reviravolta nas organizações com relação as funções administrativas nas quais ela passará a ocupar. O autor afirma que há um ponto de inflexão onde $30 \%$ das auditorias corporativas serão realizadas por robôs de IA até o ano 2025, isso acontecerá devido a IA ter facilidade de fazer correspondências de padrões e automatizar processos, o que faz a adoção da tecnologia ser recomendável. Essa introdução da IA cada vez mais no mercado e nas organizações, tem como aspectos positivos a redução de custos, ganhos de eficiência e a facilidade de pequenas empresas que exploram fortemente $\mathrm{O}$ aspecto da inovação, mas pontos negativos também são observados, tais como: perda de postos de trabalho, prestação de contas e responsabilidade, mudanças legais, de relatos financeiros e riscos.

\section{Big Data}

O ambiente organizacional vem passando por um momento de crescimento na quantidade de dados que são coletados dos ambientes interno e externo, e estão sendo feitos vários esforços com o intuito de ampliar as áreas teóricas que envolvem a capacidade e aplicação da teoria da informação (Junior, Maçada, Brinkhues, \& Dolci, 2015). Hoje o grande desafio é justamente criar mecanismos que permitam um processamento e uma análise dessa grande quantidade de dados (Wolfert et al., 2017).

O Big Data está emergindo como um tema relevante entre estudiosos e profissionais, e é definido como uma 
abordagem holística para gerenciar, processar e analisar os dados em cinco dimensões, e que tem como objetivo permitir a entrega de valor de forma sustentada, medir desempenho, criar competências e melhorar o processo decisório. O big data permite a melhora da eficiência e eficácia das organizações, e permite o processo de tomada de decisão com base em evidências e não intuição (McAfee \& Brynjolfsson, 2012).

As dimensões do Big Data são denominadas de " $5 \mathrm{Vs}$ ", são elas: Volume - satisfação, acessibilidade aos dados; Variedade - diversidade de fontes e tipos de dados; Velocidade - tempo de acesso à informação e a tomada de decisão; Veracidade - confiança na exatidão apresentada pelos dados; e Valor - o que as informações melhoram nos resultados, valor financeiro utilizado para conseguir obter dados com um bom nível de qualidade (Braganza, Brooks, Nepelski, Ali, \& Moro, 2017; Junior et al., 2015; Maçada \& Canary, 2014; McAfee \& Brynjolfsson, 2012; Sivarajah, Kamal, Irani, \& Weerakkody, 2017; Venkatram \& Geetha, 2017; Wamba et al., 2017).

Conforme afirmam Maçada \& Canary (2014), ainda não existe um consenso sobre o conceito de Big Data, talvez isso aconteça conforme, dito por Venkatram \& Geetha (2017), a definição de Big Data pode variar de organização para organização, de pessoa para pessoa, dependendo de seus casos de uso e sua geração de valor a partir de suas características de dados, tais como: tamanho de dados, capacidade, competência de recursos humanos, técnicas utilizadas para análise etc.

Conforme afirmam Sivarajah et al. (2017), a magnitude de dados gerados e compartilhados pelas organizações (públicas e privadas), indústria, setores sem fins lucrativos e pesquisas científicas, aumentou de uma forma imensa. Os dados são das mais diversas fontes (estruturadas, semiestruturadas e desestruturadas), tais como: ERP, CRM, vídeos, imagens, áudio, sensores, sinais de GPS de celulares, postagens em sites de mídias sociais, twittets, blogs, sites, IoT, dentre outras (Chew, 2013; Côrte-Real, Oliveira, \& Ruivo, 2016; Dobre \& Xhafa, 2014; Erevelles, Fukawa, \& Swayne, 2016; Junior et al., 2015; Sakthivel, Parthipan, \& Dhanasekaran, 2016).

Esse incremento na quantidade de dados gerados é ainda maior devido o uso de máquinas nas atividades operacionais nas organizações. As tecnologias Big Data estão desempenhando um papel essencial nessa mudança, e cada vez mais as máquinas estão sendo equipadas com todo o tipo de sensores que medem dados em seu ambiente na qual estão inseridas (Sivarajah et al., 2017; Wolfert et al., 2017).

Para Maçada \& Canary (2014) há um crescimento exponencial no volume de dados gerados $\mathrm{e}$ com grande velocidade. Por dia, de acordo com Dobre \& Xhafa (2014), são gerados no mundo aproximadamente 2 exabytes de dados (1 exabyte é igual 1 bilhão de gigabytes), sendo aproximadamente $90 \%$ desses dados oriundos de fontes desestruturadas, e já existem estimativas que em 2020 o mundo já terá gerado 40 trilhões de gigabytes (Sivarajah et al., 2017). Felizmente, o preço do armazenamento vem tendo constante queda, Schwab (2016), afirma que há 25 anos 1 gigabyte custava aproximadamente U\$ 10,000.00, e hoje já chega próximo dos U\$ 0,03.

Com essa imensa massa de dados e com o uso do Big Data, já é possível observar que a análise desses conjuntos de dados, é quem vem sustentando novas ondas de crescimento da produtividade, inovação e aumento de clientes. O Big Data é mais do que simplesmente uma questão de quantidade de dados, é uma oportunidade para encontrar informações sobre novos e emergentes tipos de dados e conteúdos, para tornar as empresas mais ágeis e para responder questões que outrora estavam fora do alcance das organizações (Dobre \& Xhafa, 2014).

Em suma, o Big Data vem emergindo com uma poderosa ferramenta tecnológica nos dias atuais, pois dentre outras coisas, vem permitindo a evolução do processo decisório. Ele permite analisar o universo de dados em vez de alguns dados de amostra, portanto, não há resultados tendenciosos. O exemplo ocorre com as redes sociais onde se permite análises de forma muito econômica e um feedback das opiniões dos clientes de forma mais rápida. É possível construir um produto com base nas preferências dos clientes com a ajuda de Big Data (Venkatram \& Geetha, 2017).

\section{Capacidades Dinâmicas (Dynamic Capabilities)}

O tema das Capacidades Dinâmicas (CD) ou Dynamic Capabilities, vem sendo visto como um acontecimento nas organizações e despertando interesse no ambiente acadêmico, bem como no corporativo nos seus mais diversos segmentos, que vão desde a área estratégica, passando pela gestão de recursos humanos, marketing, inovação, empreendedorismo e gestão da informação e do conhecimento.

Para Fernandes et al. (2017) e Vogel \& Güttel (2013) a CD emerge atualmente como um campo de estudo 
vibrante dentro do quadro teórico baseado no gerenciamento de recursos e estratégias, e para os autores há um expressivo crescimento no número de citações e de artigos que abordam a temática "Dynamic Capabilities".

De acordo com Meirelles e Camargo (2014) e Di Stefano, Peteraf, \& Verona (2014) existe discussão para o desenvolvimento do conceito de capacidade dinâmica, pois têm percepções/variações da definição, algumas semelhantes e outras bem conflitantes sobre os condicionantes e os elementos que compõem as capacidades dinâmicas. Barreto (2010) afirma que tal proliferação de definições mostra o dinamismo gerado pelo tema e é justificado pela juventude da abordagem, mas também produz alguma confusão que pode dificultar um progresso mais efetivo da abordagem. Portanto, uma consolidação do conceito de capacidades dinâmicas parece necessária antes que outras etapas de pesquisa sejam tomadas no campo para garantir que consideradas suposições, variáveis e relacionamentos adequados.

Uma pesquisa desenvolvida por Fernandes et al. (2017), permitiu um mapeamento da estrutura intelectual em torno do conceito de capacidade dinâmica. Os autores encontraram cinco abordagens distintas: capacidades digitais, capacidades de conhecimento, capacidades de absorção, capacidades estratégicas, além de recursos e capacidades. Foi observado que a maioria das pesquisas realizadas sobre a temática capacidade dinâmica, converge para uma ou mais dessas cinco abordagens.

Também existe um consenso com relação a origem da $\mathrm{CD}$, que é a visão baseada em recursos - VBR (resourcebasedview-RBV) (Alvarenga, Leite, Freitas, \& Ruas, 2016; Barreto, 2010; Gallardo, 2009; Giniuniene \& Jurksiene, 2015; Guedes, Araújo, \& Ornellas, 2012; Ju, Park, \& Kim, 2016; Michailova \& Zhan, 2015; Panizzon, Milan, Perin, \& Sampaio, 2015; D. J. Teece, 2007; D. J. Teece, Pisano, \& Shuen, 1997; Wamba et al., 2017). Panizzon et al. (2015) afirmam que a CD tem origem também na VBC - Visão Baseada em Conhecimento (KBV Knowledge-based $V$ iew) e da visão neoschumpeteriana da firma (Augier \& Teece, 2008).

Para os primeiros autores que abordaram essa temática, Teece et al. (1997), a capacidade dinâmica consiste na habilidade de uma firma, de forma intencional, integrar, construir e reconfigurar suas competências, sejam elas, internas e externas, para se adequar aos ambientes dinâmicos. A questão central das capacidades dinâmicas está no processo através do qual desenvolve e renova as competências existentes da organização, com base em designações/decisões passadas internamente e do ambiente dinâmico.

Meirelles \& Camargo (2014) explanam que as capacidades dinâmicas são baseadas em três elementos: os processos, as posições e a trajetória. Sendo os processos, rotinas ou padronização de aprendizado que acontece de forma recorrente; as posições como ativos que a firma possui, além de relações com clientes e ambiente externo; e a trajetória no processo decisório e aproveitamento de oportunidades que surgiram no mercado ou de tecnologias. Em outra perspectiva, a capacidade de uma organização para criar, estender ou modificar sua base de recursos propositadamente (Helfat et al., 2007). Silva (2011) complementa afirmando que a organização cria, estende ou reconfigura sua base de recursos em nível de processo. As capacidades operam para expandir, modificar ou criar recursos comuns (Winter, 2003).

Teece (2007) complementa seu conceito de 1997, afirmandoqueas $\mathrm{CD}$ permitemasorganizações sentirem e moldarem oportunidades e ameaças; aproveitarem oportunidades e manterem a competitividade através do aprimoramento, combinação, proteção e, quando necessário, reconfiguração dos ativos intangíveis e tangíveis da empresa comercial. No conceito inicial de Teece et al. (1997), conforme afirmam Meirelles \& Camargo (2014), é caracterizado com uma visão multidisciplinar, perpassando dos limites da estratégia convencional, e inserindo nesse contexto áreas variadas, como a inovação e a aprendizagem organizacional.

Já Eisenhardt \& Martin (2000), discorrem a relevância dos processos para as capacidades dinâmicas, para eles são os processos da empresa que utilizam recursos, especialmente os processos, são usados para integrar, reconfigurar, obter e liberar recursos, e para combinar e até mesmo criar mudanças de mercado. As capacidades dinâmicas, portanto, são as rotinas organizacionais e estratégicas pelas quais as empresas conseguem novas configurações de recursos à medida que os mercados emergem, colidem, dividem, evoluem ou até mesmo morrem. Uma característica relevante é que a CD aborda, é a questão da rápida capacidade adaptativa das organizações perante um mercado competitivo e a busca pela vantagem competitiva nesse cenário variável com mudanças, sobretudo, tecnológicas (Arndt \& Norbert, 2015; Barreto, 2010; Meirelles \& Camargo, 2014; D. J. Teece, 2007; D. J. Teece et al., 1997). 
Já Teece (2007) afirma que há três capacidades sustentadoras das CD, que são: a firma possuir a capacidade de observar o contexto na qual está inserida; também possuir a capacidade de tirar proveito das chances que surgem; e, capacidade de gerenciar e transformações que venham a ocorrer no ambiente organizacional.

Meirelles \& Camargo (2014) contribuem resumindo as definições de capacidades dinâmicas, como a implicação de esforços de mudança e inovação, com intuito de buscar, criar, integrar, renovar, recriar ou reconfigurar, selecionar e implantar recursos, mediante a perspectiva de Helfat et al. (2007), de habilidades e competências na perspectiva de Teece et al. (1997), das capacidades dinâmicas como processos e rotinas na percepção de Teece (2007) ou de capacidades na ótica de Wang \& Ahmed (2007).

Já na visão das capacidades dinâmicas, atuando como rotinas e processos, Teece (2007) afirma a necessidade da existência de algumas capacidades que estão relacionadas com processos, indo de acordo com Eisenhardt \& Martin (2000), e que podem: atuar analisando o ambiente externo na qual a firma está inserida; aproveitar as chances/oportunidades detectadas; e gerenciar ameaças e transformações decorrentes das mudanças organizacionais. Abaixo segue quadro 1 com a descrição dos processos para as capacidades dinâmicas de acordo com Teece (2007).

Quadro 1. Capacidades Dinâmicas e seus Processos

\begin{tabular}{|c|c|}
\hline Capacidades & Processos \\
\hline $\begin{array}{l}\text { - Capacidade de atuar analisando o ambiente externo } \\
\text { na qual está inserida } \\
\text { (Sensing) }\end{array}$ & $\begin{array}{l}\text { - Processos para direcionar trabalhos internos de P\&D; } \\
\text { - Processos de buscar fornecedores para complementar as } \\
\text { inovações da organização; } \\
\text { - Processos para buscar desenvolvimentos científicos e } \\
\text { tecnológicos externos à firma; } \\
\text { - Processos para reconhecer segmentos de mercado alvo, } \\
\text { mudando as necessidades dos clientes e gerando inovações } \\
\text { direcionadas para os clientes. }\end{array}$ \\
\hline $\begin{array}{l}\text { - Capacidade de aproveitar as chances/oportunidades } \\
\text { detectadas (Seizing) }\end{array}$ & $\begin{array}{l}\text { - Processos voltados para soluções para o cliente; } \\
\text { - Processos de seleção das fronteiras organizacionais; } \\
\text { - Processos para seleção de protocolos de tomada de decisões; } \\
\text { - Processos para construir lealdade de comprometimento. }\end{array}$ \\
\hline $\begin{array}{l}\text { - Capacidade de gerenciar ameaças e transformações } \\
\text { decorrentes das mudanças organizacionais (Managing } \\
\text { threats/transforming) }\end{array}$ & $\begin{array}{l}\text { - Processos de descentralização e decomposição; } \\
\text { - Processos de coespecialização; } \\
\text { - Processos de governança } \\
\text { - Processos de gerenciamento do conhecimento. }\end{array}$ \\
\hline
\end{tabular}

Fonte: Adaptado de Teece (2007)

Em suma, a capacidade dinâmica é o agrupamento de habilidades, comportamentos e capacidades organizacionais, assim como processos e rotinas, que levam a empresa a se diferenciar no mercado competitivo frente aos seus concorrentes. E conforme afirma Teece (2007), embora o desempenho de longo prazo da empresa seja determinado, de alguma forma pelo modo como o ambiente empresarial (externo) recompensa seu patrimônio, o desenvolvimento e o exercício de capacidades dinâmicas (internas) estão no centro do sucesso empresarial ou na sua falha.

\section{Constructo da Pesquisa}

Com o conhecimento adquirido no referencial teórico sobre Transformação Digital, mais especificamente alguns dos seus elementos que podem se relacionar diretamente, Io'T, Big Data e Inteligência Artificial, e 
das Capacidades Dinâmicas, dentre outros, e com $\mathrm{o}$ intuito de alcançar o objetivo da pesquisa, foi desenvolvido um modelo conceitual com base nas Capacidades Dinâmicas de Teece (2007) que são: Capacidade de analisar o ambiente externo na qual está inserida (Sensing); Capacidade de aproveitar as chances/oportunidades detectadas (Seizing); e Capacidade de gerenciar ameaças e transformações decorrentes das mudanças organizacionais (Managing threats/transforming).

Também será utilizada na pesquisa a matriz de importância $\mathrm{x}$ desempenho/performance, que é um dos modelos de avaliação de qualidade da satisfação do cliente, e visa detectar se os serviços/produtos oferecidos estão de acordo com as expectativas e/ ou necessidades do cliente. Segundo Martilla \& James (1977) o modelo de análise e importância x desempenho/performance, também chamada de matriz de oportunidades, é um método de identificação de oportunidades de melhoria.

Portanto, a figura 1, representa o constructo da pesquisa, onde estão relacionados os temas da transformação digital e das capacidades dinâmicas.

Figura 1. Constructo da pesquisa

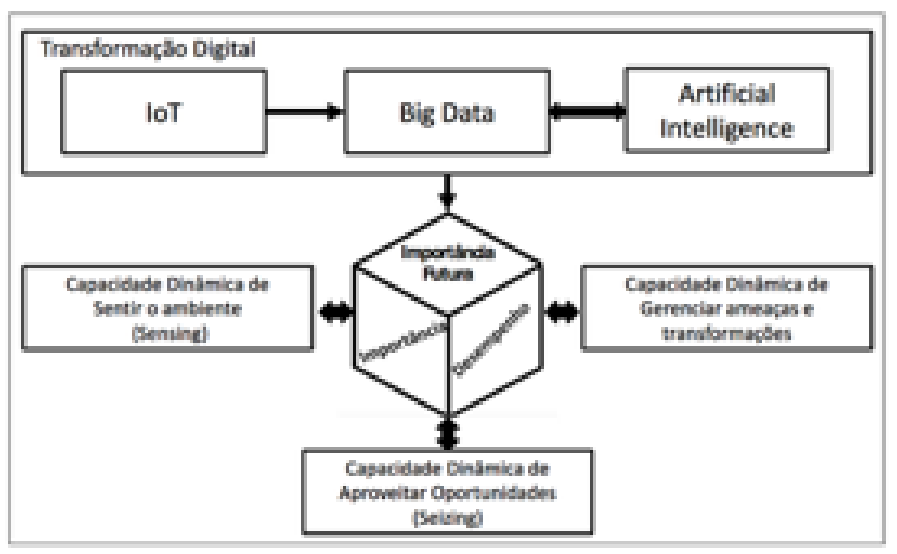

Fonte: Dados da pesquisa (2017).

Em parte do modelo será utilizada a matriz importância $\mathrm{x}$ desempenho, com o acréscimo de uma dimensão denominada de importância futura até 2025 na percepção dos respondentes. Essa matriz tridimensional se faz necessária, pois os elementos da transformação digital, conforme afirmam Kane et al. (2015), ainda se encontram em fase de amadurecimento nas organizações e essa terceira dimensão trará a perspectiva de importância dessas tecnologias sobre as capacidades dinâmicas nos próximos 7 anos, ou seja, até 2025, ano que serão detectados, segundo Schwab (2016), alguns pontos de inflexão da quarta revolução industrial. Para permitir uma visualização em duas dimensões, o desempenho atual será alocado com a importância atual e a perspectiva de importância até 2025.

\section{Metodologia}

O presente estudo se caracterizou como exploratório e descritivo, devido buscar identificar possíveis relações e diferenças entre um conjunto de variáveis e sem necessariamente se preocupar com o quesito da causalidade.

Quanto à natureza da pesquisa e abordagem ao problema, foi feita uma pesquisa quantitativa, utilizando o método de pesquisa survey descritiva. Quanto ao momento de coleta da pesquisa, foi utilizado o corte transversal (cross-sectional study) em um só momento cuja pretensão foi de descrever e analisar o estado das variáveis em um dado momento.

Para pesquisa quantitativa a amostragem utilizada foi a não-probabilística e seus elementos foram selecionados de acordo com a conveniência do pesquisador. Para a aplicação dos questionários com questões fechadas e abertas, foi utilizado um instrumento eletrônico de aplicação de questionários. O link foi enviado para profissionais das áreas de TI e Administração do Rio Grande do Norte por e-mail e também encaminhado para grupos fechados no Facebook de profissionais das duas áreas. Foram enviados para aproximadamente 350 profissionais. Foram respondidos 72 questionários, que após análise e exclusão de questionários preenchidos de forma incompleta e retirado os questionários respondidos por pessoas que não eram gestores de negócio ou TI, restaram 53 questionários válidos, somente dos respondentes que afirmaram serem gestores de TI ou de Negócio.

Um teste piloto do questionário foi enviado para 2 alunos de doutorado em administração com conhecimento na área de tecnologia e inovação. Também o instrumento foi submetido a avaliação de 2 doutores com experiência em instrumentos quantitativos. Após as sugestões, as considerações foram acatadas e implementadas no instrumento de pesquisa.

Para Malhotra (2001), a primeira providência empírica adotada foi a determinação da confiabilidade de consistência interna da escala do tipo-Likert, através 
do Alfa de Cronbach e que esse coeficiente varia de 0 a 1 e indica confiabilidade insatisfatória de consistência interna quando fica igual ou menor que 0,6. O alfa de Cronbach obtido foi relativamente alto para as questões que envolvem as capacidades dinâmicas, sendo 0,925 para as 9 questões com escala do tipoLikert. Quando separados por categorias, foi obtido o valor de 0,925 para questões relativas a IoT, 0,945 para Big Data e 0,878 para Inteligência Artificial.

\section{Análise e interpretação dos resultados}

Geralmente a estatística descritiva, segundo Crespo (2010), é utilizada em pesquisas bibliográficas, documentais, experimentais e em pesquisas descritivas, pois emprega evidências quantitativas ou quantificáveis.

\section{Perfil dos Respondentes}

$\mathrm{Na}$ estatística descritiva, observou-se uma maior participação de respondentes de grandes empresas $(50,9 \%)$, que somado ao percentual de médias empresas $(17 \%)$, representam a maioria dos respondentes com $67,9 \%$. Já microempresa representaram 17\%, e pequenas empresas com o menor percentual de $15,1 \%$. Dessas empresas, $67,9 \%$ são nacionais e $32,1 \%$ não multinacionais. Com relação ao tipo de entrega que a empresa faz para seu cliente, foi identificado o percentual de 39,6\% para "Produto e Serviço", seguido por somente "Serviço" com 34\% e por "Produto" com 14\%. O que representa de forma semelhante as características da região de Natal-RN onde foi desenvolvida a pesquisa, onde há uma predominância por serviços e baixa atividade industrial na fabricação de produtos.

Os pesquisadores optaram por selecionar somente os questionários respondidos por gestores, sejam eles de negócio ou TI, os resultados indicaram uma maior predominância de gestores de negócio com $62,3 \%$, enquanto que gestores de TI totalizaram $37,7 \%$. Também foi observado o nível hierárquico relativo ocupado pelos respondentes. $\mathrm{O}$ modelo utilizado foi com base em Pereira, Sousa Filho, \& Lucian (2009), no qual a escala varia de 0 a 1 , sendo 0 (zero) o nível mais alto hierárquico e 1 o último nível (mais operacional). Neste índice, o nível hierárquico que ocupa atualmente é dividido pelo número total de níveis hierárquicos da organização e pode variar de empresa para empresa. Para cálculo do índice do nível hierárquico foi utilizado o seguinte cálculo: indicehierarquico $=($ nivelhierarquico-1) $/$ (niveishierarquicos-1), para niveishierarquivos $>1$ o indicehierarquico $=1$, para níveishieraquicos $=1$. A média obtida foi de 0,6 , onde aproximadamente $51 \%$ dos respondentes possuem um nível hierárquico que varia de 0 a 0,5 , ou seja, a maioria dos respondentes faz parte de níveis hierárquicos superiores da organização. Sugere-se, também, a participação do percentual de $17 \%$ por parte dos gestores principais da organização (índice hierárquico 0 - zero).

\section{Matriz Importância (atual e futura) x Desempenho}

Segundo Tontini \& Theiss (2005) o modelo de análise de importância $\mathrm{x}$ desempenho, também chamada de matriz de oportunidades, é um método de identificação de oportunidades de melhoria, criada por Martilla e James em 1977.

Para a pesquisa, a matriz foi utilizada com o intuito de analisar a importância atribuída atualmente, o desempenho e a perspectiva de importância futura até 2025 na percepção dos gestores de negócio e de TI, para o uso das tecnologias IoT, Big Data e IA, relacionados com os processos das capacidades dinâmicas que envolvem, respectivamente: A capacidade de analisar o ambiente externo na qual está inserida (Sensing); Capacidade de aproveitar as chances / oportunidades detectadas (Seizing); e Capacidade de gerenciar ameaças e transformações decorrentes das mudanças organizacionais (Managing threats/ transforming), conforme a Teoria das Capacidades Dinâmicas formulada por Teece (2007). Foi utilizada uma escala tipo-Likert de 7 pontos, que variou de 1 (sem importância / nenhum desempenho) até 7 (extrema importância / excelente desempenho).

\section{Capacidade Dinâmica Sensing (analisar o ambiente)}

De acordo Teece (2007) a capacidade dinâmica Sensing, que possui processos que permitem analisar o ambiente externo na qual a organização está inserida; processos que permitem direcionar trabalhos internos de P\&D; buscar fornecedores para complementar as inovações da organização; buscar desenvolvimentos científicos e tecnológicos externos à firma; e reconhecer segmentos de mercado alvo, mudando as necessidades dos clientes e gerando inovações direcionadas para os clientes.

No quadro 2 é demonstrado através da análise das médias, medianas e modas obtidas através da análise 
da escala tipo-Likert, que dentre as 3 tecnologias (IoT, Big Data e IA), o Big Data possui melhor desempenho (mediana 4 e média 3,58), seguido da IoT (mediana 2 e média 2,11), e por último a utilização da Inteligência Artificial, com desempenho ainda incipiente ou quase sem utilização (mediana 1 e média 1,83). Os dados sugerem ainda que as 3 tecnologias são pouco utilizadas para esses tipos de processos de detecção de elementos do ambiente externo. Esse baixo uso das tecnologias com a capacidade dinâmica Sensing, pode estar relacionado as empresas dessa capital brasileira, não possuírem um ambiente com um nível de competitividade elevada, se comparado com grandes centros do Brasil. Isso é relevante devido as capacidades dinâmicas possuírem uma rápida capacidade adaptativa das organizações perante um mercado competitivo e a busca pela vantagem competitiva nesse cenário variável com mudanças, sobretudo, tecnológicas (Arndt \& Norbert, 2015; Barreto, 2010; Meirelles \& Camargo, 2014; D. J. Teece, 2007; D. J. Teece et al., 1997).

Quadro 2 . Importância atual, desempenho, importância futura da capacidade dinâmica Sensing

\begin{tabular}{|c|c|c|c|c|c|c|c|c|c|c|c|}
\hline Tecnologia & Dimensão & 1 & 2 & 3 & 4 & 5 & 6 & 7 & Média & Mediana & Moda \\
\hline \multirow[t]{3}{*}{ IoT } & $\begin{array}{l}\text { Importância } \\
\text { Atual }\end{array}$ & $24,5 \%$ & $7,5 \%$ & $9,4 \%$ & $17,0 \%$ & $17,0 \%$ & $13,2 \%$ & $11,3 \%$ & 3,79 & 4,00 & 1 \\
\hline & Desempenho & $41,5 \%$ & $18,9 \%$ & $26,4 \%$ & $13,2 \%$ & $0,0 \%$ & $0,0 \%$ & $0,0 \%$ & 2,11 & 2,00 & 1 \\
\hline & $\begin{array}{l}\text { Importância } \\
\text { (perspectiva } \\
\text { futura) }\end{array}$ & $7,5 \%$ & $5,7 \%$ & $7,5 \%$ & $9,4 \%$ & $20,8 \%$ & $24,5 \%$ & $24,5 \%$ & 5,02 & 5,00 & 6 \\
\hline \multirow[t]{3}{*}{ Big Data } & $\begin{array}{l}\text { Importância } \\
\text { Atual }\end{array}$ & $9,4 \%$ & $3,8 \%$ & $28,3 \%$ & $7,5 \%$ & $15,1 \%$ & $17,0 \%$ & $18,9 \%$ & 4,42 & 5,00 & 3 \\
\hline & Desempenho & $18,9 \%$ & $13,2 \%$ & $5,7 \%$ & $28,3 \%$ & $20,8 \%$ & $13,2 \%$ & $0,0 \%$ & 3,58 & 4,00 & 4 \\
\hline & $\begin{array}{l}\text { Importância } \\
\text { (perspectiva } \\
\text { futura) }\end{array}$ & $5,7 \%$ & $1,9 \%$ & $15,1 \%$ & $11,3 \%$ & $18,9 \%$ & $24,5 \%$ & $22,6 \%$ & 5,00 & 5,00 & 6 \\
\hline \multirow[t]{3}{*}{$\begin{array}{c}\text { Inteligência } \\
\text { Artificial }\end{array}$} & $\begin{array}{l}\text { Importância } \\
\text { Atual }\end{array}$ & $13,2 \%$ & $26,4 \%$ & $22,6 \%$ & $26,4 \%$ & $3,8 \%$ & $7,5 \%$ & $0,0 \%$ & 3,04 & 3,00 & 2 \\
\hline & Desempenho & $50,9 \%$ & $26,4 \%$ & $15,1 \%$ & $3,8 \%$ & $3,8 \%$ & $0,0 \%$ & $0,0 \%$ & 1,83 & 1,00 & 1 \\
\hline & $\begin{array}{l}\text { Importância } \\
\text { (perspectiva } \\
\text { futura) }\end{array}$ & $9,4 \%$ & $5,7 \%$ & $13,2 \%$ & $5,7 \%$ & $18,9 \%$ & $20,8 \%$ & $26,4 \%$ & 4,87 & 5,00 & 7 \\
\hline
\end{tabular}

Fonte: Dados da pesquisa (2017)

De acordo com Dobre \& Xhafa (2014), as tecnologias que envolvem o Big Data estão mais acessíveis as organizações, o que pode estar colaborando com o desempenho melhor dentre as 3 tecnologias pesquisadas. Além disso, o Big Data favorece a captura de dados e informações externas, que é o foco principal da capacidade dinâmica Sensing. Como exemplo, ocorre com as redes sociais onde se permite análises de forma muito econômica e opiniões do ambiente externo de forma mais rápida (Venkatram \& Geetha, 2017).

Já com relação a importância atual, observou-se que os gestores percebem as três tecnologias como importantes atualmente, mesmo as que estão com baixo desempenho. E que a perspectiva de importância futura possui um acrescimento considerável, o que sugere que os respondentes acreditam que o IoT, Big Data e a IA serão mais importantes nos processos da capacidade dinâmica de detecção do ambiente externo, novamente com os percentuais mais altos para a tecnologia Big Data.

Outra questão que pode indicar a maior utilização e importância (atual e futura) do Big Data, é que essa tecnologia tem forte relação com o que Teece (2007) defende com relação aos processos da capacidade dinâmica de analisar o ambiente (sensing), onde para obter êxito, as organizações precisam interpretar a informação disponível em qualquer forma que apareça, seja através de gráficos, imagens, notícias de avanços científicos e 
tecnológicos, ou a angústia expressada por um cliente frustrado. É preciso acumular e depois filtrar informações de contatos profissionais e sociais para criar uma conjectura ou uma hipótese sobre a evolução provável das tecnologias, necessidades do cliente e respostas do mercado. Esta tarefa envolve monitorar desenvolvimentos tecnológicos internos e externos e avaliar as necessidades dos clientes, expressas e latentes, bem como a aprendizagem, interpretação e atividade criativa (Dobre \& Xhafa, 2014). Essa detecção (sensing) é essencial para que a empresa se sustente a longo prazo à medida que os clientes, concorrentes e tecnologias mudam (Teece, Peteraf, \& Leih, 2016). É relevante observar que a tecnologia Big Data possui maiores médias e medianas na importância atual, futura e desempenho, pois o Big Data permite a melhora da eficiência e eficácia das organizações, e permite o processo de tomada de decisão com base em evidências e não intuição (McAfee \& Brynjolfsson, 2012).

\section{Capacidade Dinâmica Seizing (aproveitar oportunidades)}

Os processos voltados para soluções aos clientes, seleção das fronteiras organizacionais, seleção de protocolos de tomada de decisões e relacionados com a construção de lealdade e comprometimentos dos funcionários, fazem parte das capacidades dinâmicas Seiz̨ing, que permitem a mobilização de recursos para atender às necessidades e oportunidades aproveitando-as (Teece, 2007; Teece, Peteraf, \& Leih, 2016).

No quadro 3 identifica-se percentuais mais elevados nas 3 tecnologias se comparadas com as capacidades dinâmicas sensing. Novamente há uma predominância no desempenho da tecnologia Big Data em relação a IoT e IA, com médias 3,72, 2,53 e 1,72, e medianas 4, 2 e 1, respectivamente.

Quadro 3 . Importância atual, desempenho, importância futura da capacidade dinâmica Seizing

\begin{tabular}{|c|c|c|c|c|c|c|c|c|c|c|c|}
\hline Tecnologia & Dimensão & 1 & 2 & 3 & 4 & 5 & 6 & 7 & Média & Mediana & Moda \\
\hline \multirow[t]{3}{*}{ IoT } & $\begin{array}{l}\text { Importância } \\
\text { Atual }\end{array}$ & $20,8 \%$ & $9,4 \%$ & $9,4 \%$ & $17,0 \%$ & $22,6 \%$ & $13,2 \%$ & $7,5 \%$ & 3,81 & 4,00 & 5 \\
\hline & Desempenho & $28,3 \%$ & $24,5 \%$ & $24,5 \%$ & $11,3 \%$ & $11,3 \%$ & $0,0 \%$ & $0,0 \%$ & 2,53 & 2,00 & 1 \\
\hline & $\begin{array}{l}\text { Importância } \\
\text { (perspectiva } \\
\text { futura) }\end{array}$ & $7,5 \%$ & $13,2 \%$ & $9,4 \%$ & $7,5 \%$ & $26,4 \%$ & $17,0 \%$ & $18,9 \%$ & 4,58 & 5,00 & 5 \\
\hline \multirow[t]{3}{*}{ Big Data } & $\begin{array}{l}\text { Importância } \\
\text { Atual }\end{array}$ & $5,7 \%$ & $13,2 \%$ & $18,9 \%$ & $3,8 \%$ & $22,6 \%$ & $20,8 \%$ & $15,1 \%$ & 4,47 & 5,00 & 5 \\
\hline & Desempenho & $15,1 \%$ & $5,7 \%$ & $20,8 \%$ & $24,5 \%$ & $20,8 \%$ & $11,3 \%$ & $1,9 \%$ & 3,72 & 4,00 & 4 \\
\hline & $\begin{array}{l}\text { Importância } \\
\text { (perspectiva } \\
\text { futura) }\end{array}$ & $3,8 \%$ & $7,5 \%$ & $11,3 \%$ & $7,5 \%$ & $15,1 \%$ & $20,8 \%$ & $34,0 \%$ & 5,21 & 6,00 & 7 \\
\hline \multirow[t]{3}{*}{$\begin{array}{c}\text { Inteligência } \\
\text { Artificial }\end{array}$} & $\begin{array}{l}\text { Importância } \\
\text { Atual }\end{array}$ & $18,9 \%$ & $18,9 \%$ & $22,6 \%$ & $17,0 \%$ & $13,2 \%$ & $3,8 \%$ & $5,7 \%$ & 3,21 & 3,00 & 3 \\
\hline & Desempenho & $52,8 \%$ & $32,1 \%$ & $7,5 \%$ & $5,7 \%$ & $1,9 \%$ & $0,0 \%$ & $0,0 \%$ & 1,72 & 1,00 & 1 \\
\hline & $\begin{array}{l}\text { Importância } \\
\text { (perspectiva } \\
\text { futura) }\end{array}$ & $1,9 \%$ & $13,2 \%$ & $11,3 \%$ & $24,5 \%$ & $15,1 \%$ & $11,3 \%$ & $22,6 \%$ & 4,62 & 4,00 & 4 \\
\hline
\end{tabular}

Fonte: Dados da pesquisa (2017)

Essas médias e medianas superiores no desempenho das 3 tecnologias para as capacidades de aproveitamento de oportunidades detectadas no ambiente interno e externo da organização, sugerem o maior uso de tecnologias para esses processos, isso está de acordo com o que afirma Teece (2007), que informa que para abordar as oportunidades (Seiz̨ing), tem que haver a manutenção e o aprimoramento das competências tecnológicas e dos recursos complementares e, em seguida, quando a oportunidade está madura, investindo fortemente nas tecnologias e designs mais prováveis para alcançar uma maior aceitação do mercado. 
Para a capacidade dinâmica de aproveitar oportunidades, observou-se que o desempenho e importância (atual e futura) da utilização do Big Data, foi superior as demais capacidades dinâmicas e tecnologias, esse fato pode estar ocorrendo devido essa capacidade dinâmica ter forte relação com o processo de tomada de decisão, através da definição e utilização de protocolos de decisão. De acordo com Vieira, Pedrosa, \& Soares (2017), Erevelles, Fukawa, \& Swayne (2016) e Venkatram \& Geetha (2017), a justificativa para utilização da tecnologia Big Data é devido sua utilização do processo decisório, onde se busca melhores decisões, com o intuito de aumentar a probabilidade de êxito e minimização do risco. Também vale ressaltar que a tecnologia Big Data estão desempenhando um papel essencial nessa mudança, e cada vez mais as máquinas estão sendo equipadas com todo o tipo de sensores que medem dados em seu ambiente na qual estão inseridas (Sivarajah et al., 2017; Wolfert et al., 2017).

\section{Capacidade Dinâmica Managing Threats/Transforming (gerenciar ameaças e oportunidades)}

De acordo com Meirelles \& Camargo (2014) e Teece (2007) existe uma terceira capacidade que serve de fundamentação para as capacidades dinâmicas, que é a denominada capacidade de gerenciar ameaças e transformações (Managing Threats/Transforming), e sua composição envolve processos que abordam questões de descentralização e decomposição da estrutura organizacional; a coespecialização de ativos da organização; e aspectos relacionados com aprendizagem, compartilhamento do conhecimento, além de governança.

Assim como nas capacidades Sensing e Seizing, observou-se que o desempenho da tecnologia Big Data foi superior a Io'T e IA. Foi observado quando comparada a média do desempenho da tecnologia de Io'T nesta capacidade dinâmica com as demais, que seu desempenho foi melhor, conforme demonstra o quadro 4. Também vale destacar o alto percentual de respondentes que não há desempenho algum da IA para essa capacidade dinâmica (50,9\%). Isso sugere a imaturidade ainda do uso da inteligência artificial nas empresas pesquisadas.

Quadro 4 . Importância atual, desempenho, importância futura da capacidade dinâmica Managing Threats/Transforming

\begin{tabular}{|c|c|c|c|c|c|c|c|c|c|c|c|}
\hline Tecnologia & Dimensão & 1 & 2 & 3 & 4 & 5 & 6 & 7 & Média & Mediana & Moda \\
\hline \multirow[t]{3}{*}{ IoT } & Importância Atual & $22,6 \%$ & $13,2 \%$ & $7,5 \%$ & $18,9 \%$ & $17,0 \%$ & $17,0 \%$ & $3,8 \%$ & 3,60 & 4,00 & 1 \\
\hline & Desempenho & $41,5 \%$ & $9,4 \%$ & $11,3 \%$ & $15,1 \%$ & $11,3 \%$ & $11,3 \%$ & $0,0 \%$ & 2,79 & 2,00 & 1 \\
\hline & $\begin{array}{l}\text { Importância (perspectiva } \\
\text { futura) }\end{array}$ & $13,2 \%$ & $11,3 \%$ & $3,8 \%$ & $13,2 \%$ & $9,4 \%$ & $35,8 \%$ & $13,2 \%$ & 4,55 & 5,00 & 6 \\
\hline \multirow[t]{3}{*}{ Big Data } & Importância Atual & $7,5 \%$ & $7,5 \%$ & $13,2 \%$ & $15,1 \%$ & $28,3 \%$ & $15,1 \%$ & $13,2 \%$ & 4,47 & 5,00 & 5 \\
\hline & Desempenho & $28,3 \%$ & $11,3 \%$ & $13,2 \%$ & $17,0 \%$ & $15,1 \%$ & $5,7 \%$ & $9,4 \%$ & 3,34 & 3,00 & $T$ \\
\hline & $\begin{array}{l}\text { Importância (perspectiva } \\
\text { futura) }\end{array}$ & $3,8 \%$ & $1,9 \%$ & $7,5 \%$ & $9,4 \%$ & $18,9 \%$ & $28,3 \%$ & $30,2 \%$ & 5,43 & 6,00 & 7 \\
\hline \multirow{3}{*}{$\begin{array}{l}\text { Inteligência } \\
\text { Artificial }\end{array}$} & Importância Atual & $9,4 \%$ & $24,5 \%$ & $22,6 \%$ & $18,9 \%$ & $5,7 \%$ & $17,0 \%$ & $1,9 \%$ & 3,45 & 3,00 & 2 \\
\hline & Desempenho & $50,9 \%$ & $28,3 \%$ & $11,3 \%$ & $7,5 \%$ & $1,9 \%$ & $0,0 \%$ & $0,0 \%$ & 1,81 & 1,00 & $T$ \\
\hline & $\begin{array}{l}\text { Importância (perspectiva } \\
\text { futura) }\end{array}$ & $3,8 \%$ & $9,4 \%$ & $20,8 \%$ & $13,2 \%$ & $9,4 \%$ & $17,0 \%$ & $26,4 \%$ & 4,72 & 5,00 & 7 \\
\hline
\end{tabular}

Fonte: Dados da pesquisa (2017)

Com relação a importância atual e importância na perspectiva futura, foi detectado em ambas uma menor importância atribuída a tecnologia IoT, quando comparada com as outras capacidades dinâmicas. Talvez isso se deva ao fato dos processos que envolvem essa capacidade dinâmica serem relacionados com tomada de decisão (centralização ou descentralização), com cruzamentos de informações de ativos diferentes, com aprendizagem, compartilhamento e a integração do conhecimento (Meirelles \& Camargo, 2014). Essas características estão mais relacionadas com análises, o que pode sugerir a maior utilização de soluções de Big Data e posteriormente com IA. Padrão justamente este observado, onde há Big Data e IA, percebeu-se um aumento na importância 
atual e futura em relação às capacidades Sensing e Seizing. Para Gunasekaran et al. (2017) o Big Data atua positivamente no compartilhamento de informações, integração e transformação na cadeia na qual a organização faz parte, além do desempenho organizacional.

O desempenho superior da tecnologia Big Data neste microfundamento pode favorecer o processo de aprendizagem da organização, que de acordo com Barrales-Molina, Bustinza, \& Gutiérrez-Gutiérrez (2013), existe influência e efeito significativo dos mecanismos de aprendizagem na geração das capacidades dinâmicas. Também vale destacar o alto percentual de respondentes que não há desempenho algum da IA para essa capacidade dinâmica (50,9\%), se comparada com as outras tecnologias. Isso sugere a imaturidade ainda do uso da inteligência artificial nas empresas pesquisadas.

\section{Matriz Importância (atual e perspectiva futura) $x$ Desempenho atual}

Optou-se no trabalho por dividir a matriz de importância e desempenho em duas partes. A primeira utilizando a importância atual versus desempenho atual observado. E a segunda, a Importância na perspectiva futura versus desempenho atual observado. Foram definidos 4 quadrantes em cada gráfico, que foram divididos da seguinte forma: de 1,0 a 3,9 (média) Menor Importância/Menor Desempenho e de 4,0 a 7,0 (média) Maior Importância/Maior Desempenho. Para melhor compreensão, segue abaixo a legenda:

IAA - Io'T com a CD de Analisar o ambiente (Sensing) IAO - IoT com a CD de Aproveitar as Oportunidades (Seizing)

IGA - IoT com a CD de Gerir Ameaças (Managing Threats/Transforming)

BAA - Big Data com a CD de Analisar o ambiente (Sensing)

BAO - Big Data com a CD de Aproveitar as Oportunidades (Seiæing)

BGA - Big Data com a CD de Gerir Ameaças (Managing Threats/Transforming)

AAA - Inteligência Artificial com a CD de Analisar o ambiente (Sensing)

AAO - Inteligência Artificial com a CD de Aproveitar as Oportunidades (Seizing)
AGA - Inteligência Artificial com a CD de Gerir Ameaças (Managing Threats/Transforming)

Ao analisar a figura 2, composto pela Importância Atual versus Desempenho atual, observar-se no quadrante de menor importância e menor desempenho, as tecnologias IoT e Inteligência Artificial, para as 3 capacidades dinâmicas. Já Big Data é visto com uma tecnologia com um maior desempenho nas capacidades dinâmicas.

Figura 2 . Matriz Importância atual x Desempenho atual

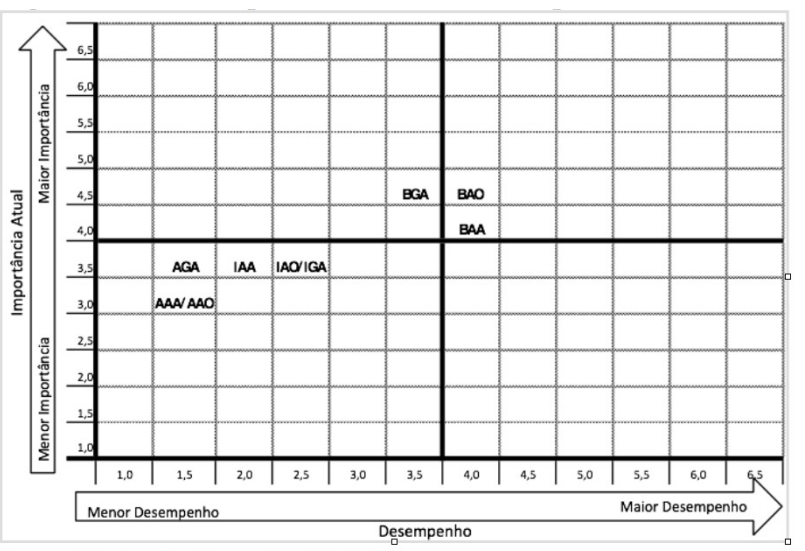

Fonte: Dados da Pesquisa (2017)

Quando analisado com a importância, observa-se que dentre os respondentes as tecnologias de IoT e Inteligência artificial se encontram no quadrante de menor importância atual, ou seja, esses dois serviços além de terem menor desempenho, também são vistos com menor importância, para as três capacidades dinâmicas (analisar o ambiente, aproveitar a oportunidade e gerir ameaças/oportunidades). Também fica sugerido que a Inteligência Artificial tem o menor desempenho dentre as 3 tecnologias. Provavelmente o baixo desempenho esta relacionado com a pouca utilização, devido justamente a questão de maturidade da própria tecnologia, conforme afirma Makridakis (2017) que a revolução proporcionada pela IA estará acontecendo no espaço de tempo dos próximos 20 anos, e que há dois aspectos relevantes para lidar com esses desafios da IA, o primeiro é que os perigos são bem compreendidos, e o segundo, é há muito tempo para debater os problemas e tomar ações sábias para lidar com eles efetivamente.

Para duas das capacidades dinâmicas, analisar o ambiente (Sensing) e aproveitar as oportunidades 
(Seizing), a tecnologia de Big Data se enquadrou no quadrante de maior desempenho e maior importância. Provavelmente isso se deva ao fato dos gestores já possuírem maior conhecimento da tecnologia, por ser a mais utilizada e vivenciada. Os gestores, provavelmente, perceberam que à medida que os dados se tornam maiores, mais complexos e mais inexplicáveis, há uma necessidade de auxiliar capacidade mental dos humanos para analisar/ filtrar essa grande quantidade de informações e conhecimento (Erevelles et al., 2016). Além disso, de acordo com McAfee \& Brynjolfsson (2012), o desafio é coletar de forma inteligente informações nessa grande massa de dados, que possui mais volume, variedade e com mais velocidade.

Já quando avaliada a figura 3 que contém a Importância (perspectiva futura até 2025) versus Desempenho atual, observa-se uma maior importância atribuída para as 3 tecnologias nas 3 capacidades dinâmicas, com maior destaque para o aumento da importância da Io'T e do Big Data. Mesmo com esse aumento da importância futura, na percepção dos gestores, vale observar a necessidade das organizações buscarem ter o cuidado nas questões que envolvem a privacidade individuais, pois como afirma Adams (2017), proteger os dados pessoais na era do Big Data e do IoT requer uma abordagem multifacetada e um maior controle do proprietário dos dados.

Figura 3 . Matriz Importância Perspectiva futura (2025) x Desempenho atual

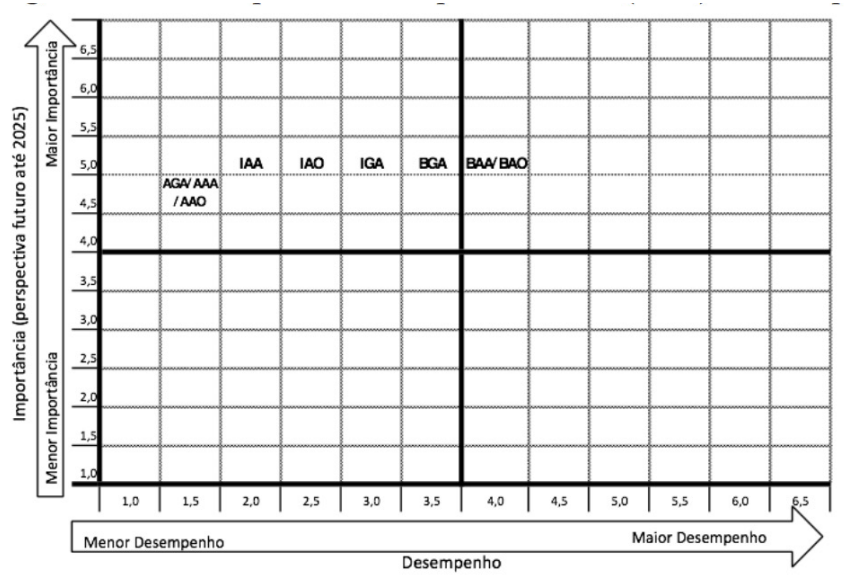

Fonte: Dados da Pesquisa (2017)

A inteligência artificial migrou do quadrante de menor importância para maior importância. Isso sugeri que os gestores de negócio e TI, possuem uma perspectiva de maior relevância dessas 3 tecnologias nas suas organizações no prazo de 7 anos (2025).

Observa-se também, que, mesmo possuindo menor desempenho atual, as tecnologias são percebidas como maior importância (atual ou futura) na atuação dos processos das capacidades dinâmicas abordadas na pesquisa. Isso pode se dever ao fato das necessidades das organizações precisarem, nos ambientes competitivos, se reconfigurarem de forma mais rápida. Com maior destaque para BAO - Big Data nos processos das capacidades dinâmicas de Aproveitar as Oportunidades e BAA - Big Data nos processos das capacidades dinâmicas de Analisar o Ambiente.

\section{Processo de Transformação Digital com uso das tecnologias IoT, Big Data e IA}

Os gestores de negócio e TI foram indagados com uma questão aberta, com relação a opinião sobre a empresa esta a passar ou passará pelo processo de transformação digital com o uso de tecnologias como IoT, Big Data e Inteligência Artificial. E o quão relevante é esse processo de transformação digital com as capacidades dinâmicas para a organização, relativamente à estrutura organizacional, processo de tomada de decisão e resultados financeiros.

Dentre as respostas, observou-se que há uma busca por implantar essas tecnologias, com intuito de inovação para melhoria do processo decisório, conforme relatos abaixo dos respondentes intitulados A e B:

\section{Respondente A:}

Estamos a todo tempo buscando inovação o tempo todo. Precisamos buscar o uso dessas tecnologias para melhorar o nosso processo de tomada de decisão e também melhorar nossos processos para garantirmos melhor prestação de serviços.

\section{Respondente B:}

Essas tecnologias mudam a forma de ver e entender a empresa e mudam também as oportunidades de negócios, não apenas do ponto de vista de tomada de decisão, mas também como potenciais produtos/serviços a fazerem parte do portfólio da empresa. O desenvolvimento dessas tecnologias está trazendo benefícios gerenciais diretos internos e ao mesmo tempo se cria na 
empresa o know-how necessário para o aproveitamento dessas tecnologias em produtos e serviços.

Com relação ao uso das tecnologias, assim como aconteceu nos dados quantitativos, observou-se nos relatos que a ferramenta Big Data já é uma realidade e a IA ainda se encontra um pouco distante da realidade local, conforme demonstram os relatos abaixo dos respondentes $\mathrm{C}, \mathrm{D}$ e $\mathrm{E}$ :

\section{Respondente C:}

Big Data principalmente é uma solução fundamental para meu tipo de negócio. Ela ajudará fortemente o processo decisório da minha empresa o que acarretará, possivelmente em melhores receitas financeiras, pois as decisões serão mais assertivas. Em um momento mais distante a inteligência artificial ajudará também nessas decisões.

\section{Respondente D:}

Big Data hoje é nossa maior realidade, IoT e inteligência artificial demorará mais para utilizarmos.

\section{Respondente E:}

O Big Data é uma realidade que não pode ser desprezada. Ela oferece a organização uma vasta gama de oportunidades que podem impacta positivamente nos lucros. O AI ainda não faz parte de nossos planos. Tudo ainda é muito novo, não passando de muitas especulações.

De acordo com a análise dos relatos, algumas das empresas estão passando pelo processo de Transformação Digital de forma ainda muito incipiente, com iniciativas de soluções que envolvem basicamente o Big Data. Já a IoT, e principalmente, o uso da Inteligência Artificial, ainda é algo que as organizações não estão efetivamente implementando e estão aguardando o amadurecimento dessas tecnologias. Também se observou que as iniciativas de utilização, tem como objetivo auxiliar o processo de inovação e melhoria / reconfiguração dos processos. Para Silva (2011), o uso da TI e sua capacidade de reconfigurabilidade e complementaridade, permitem a melhoria da eficiência e a efetividade do desempenho nos processos de negócio.

\section{Considerações finais}

Com o uso cada vez mais massivo da TI no ambiente empresarial com objetivo de melhorar sua eficiência, eficácia e efetividade, as organizações buscam mecanismos de aprimoramentos dos seus processos com o uso dessas tecnologias, bem como com intuito de competir em um mercado tão concorrido, onde em toda parte surge uma estratégia com finalidade de criar ou manter uma vantagem competitiva.

No processo de transformação digital, conforme afirmam Matt, Hess, \& Benlian (2015), nos últimos anos, empresas em quase todas as indústrias realizaram várias iniciativas para explorar novas tecnologias digitais e explorar seus benefícios. Por consequência, há transformações de operações comerciais importantes e afeta produtos e processos, bem como estruturas organizacionais e conceitos de gerenciamento.

De acordo com a pesquisa e do seu objetivo, as organizações, na sua maioria grandes e médias empresas $(67,9 \%)$, do Estado do Rio Grande do Norte, na percepção de gestores de negócio e de TI, estão ainda em um processo de utilização inicial das tecnologias (IoT, Big Data e IA) da denominada transformação digital.

Com relação ao desempenho e utilização, observouse que a tecnologia Big Data obteve destaque frente a IoT e IA, nas 3 capacidades dinâmicas: de analisar o ambiente (sensing); aproveitar as oportunidades (seizing) e gerir ameaças (managing threats/transforming).

O melhor desempenho observado dentre as capacidades dinâmicas da tecnologia Big Data foi referente aos processos da capacidade dinâmica de aproveitar oportunidades (seizing), que possuem relação com questões que envolvem a busca de soluções para os clientes, protocolos de tomada de decisões e rotinas para buscar construir uma maior lealdade e comprometimento dos funcionários, que segundo Teece (2007), aumenta consideravelmente o desempenho na organização. $O$ resultado sugere que isso pode estar ocorrendo devido as características do Big Data de permitir coletas e análises de uma grande massa de dados e informações, que já são geradas e compartilhadas pelas organizações, através de diversas fontes (estruturadas, semiestruturadas e desestruturadas). Além da própria quantidade de soluções no mercado que envolvem essa tecnologia. Ainda com relação a desempenho, a tecnologia de Inteligência Artificial é a que obteve menor performance, ela ainda é tida com baixa maturidade e utilização nas empresas locais. De toda forma, isso 
pode se dever pelas características das empresas, voltadas na sua maioria para prestação de serviço, onde ainda não existem muitas soluções implementadas e amadurecidas comercialmente. O desempenho da IoT nas 3 capacidades dinâmicas também ainda é incipiente, mas superou o desempenho da Inteligência Artificial.

Com relação a importância atual e futura (perspectiva até 2025), observou-se uma linearidade relacionada ao desempenho. Quanto maior o desempenho, maior foi também a importância atual e futura atribuída. De toda forma, vale destacar que a tecnologia de Inteligência Artificial, embora possua baixo desempenho e uma menor importância atual percebida, foi a tecnologia que obteve o maior gap entre a importância atual e a importância na perspectiva futura, e nas 3 capacidades dinâmicas. Os dados sugerem que embora pouco utilizada atualmente, os gestores de TI e negócio, acreditam que a importância do uso da tecnologia de inteligência artificial aumentará nos próximos 7 anos.

Com relação a importância atual e perspectiva de importância futura até 2025, para essas 3 tecnologias nos microfundamentos, observou-se novamente a tecnologia Big Data com maior destaque, seguida de Io'T e IA. Vale ressaltar que analisando os gaps existentes entre importância atual $\mathrm{x}$ importância futura, a tecnologia que possui uma diferença maior é a Inteligência Artificial, nos 3 microfundamentos. Sugere-se, que, mesmo com a baixa utilização (avaliada no desempenho), os gestores acreditam que a IA até os próximos 7 anos, terá um aumento da importância nas organizações, principalmente nos microfundamentos Seizing e Sensing, respectivamente.

Assim, foi identificado que na percepção de gestores de negócio e de TI os elementos da transformação digital, mesmo com a utilização relativamente baixa, principalmente da Io'T e IA, com melhor destaque para Big Data, são vistas como importância, seja nos dias atuais, bem como na perspectiva até 2025 , nos processos que envolvem as capacidades dinâmicas de analisar o ambiente (Sensing), aproveitar as oportunidades (Seizing) e gerir as ameaças e transformações (managing threats) transforming). Também, que algumas das empresas estão passando pelo processo de Transformação Digital de forma ainda muito incipiente, com iniciativas de soluções que envolvem basicamente o Big Data. Já a IoT, e principalmente, o uso da Inteligência Artificial, ainda é algo que as organizações não estão efetivamente implementando. Para pesquisas futuras sugere-se analisar as correlações existentes entre as tecnologias Big Data, IoT e Big Data com as capacidades dinâmicas.

\section{Referências}

ADAMS, M. (2017). Big Data and Individual Privacy in the Age of the Internet of Things, 7(4), 12-24.

ALEEM, A., \& RYAN SPROTT, C. (2012). Let me in the cloud: analysis of the benefit and risk assessment of cloud platform. Journal of Financial Crime, 20(1), 6-24. https://doi. org/10.1108/13590791311287337

ALVARENGA, M. A., LEITE, N. R. P., FREITAS, A. D. G. de, \& RUAS, R. L. (2016). Capacidades dinâmicas e vantagem competitiva em ambientes de mudanças constantes, à luz da análise do filme "Recém-chegada". REGE - Revista de Gestão, 24, 3544. https://doi.org/10.1016/j.rege.2016.06.010

ARNDT, F., \& NORBERT, B. (2015). Evolutionary and Ecological conceptualization of dynamic capabilities: Identifying elements of the Teece and Eisenhardt schools. Journal of Management \& Organization, 1-4. https://doi.org/10.1017/jmo.2015.22

ASHTON, K. (2009). That "Internet of Things" Thing. RFiD Journal, 4986. https://doi. org/10.1145/2967977

AUGIER, M., \& TEECE, D. J. (2008). Strategy as Evolution with Design: The Foundations of Dynamic Capabilities and the Role of Managers in the Economic System. Organization Studies, 29(8-9), 1187-1208. https://doi. org/10.1177/0170840608094776

BADGER, L., PAT'T-CORNER, R., \& VOAS, J. (2011). Draft Cloud Computing Synopsis and Recommendations Recommendations of the National Institute of Standards and Technology. Nist Special Publication, 117, 84. https://doi.org/2012

BARRETO, I. (2010). Dynamic Capabilities: A Review of Past Research and an Agenda for the Future. Journal of Management, 36(1), 256-280. https://doi.org/10.1177/0149206309350776

BRAGANZA, A., BROOKS, L., NEPELSKI, D., Ali, M., \& MORO, R. (2017). Resource management in Big Data initiatives: Processes and dynamic capabilities. Journal of Business Research, 70, 328-337. https://doi.org/10.1016/j.jbusres.2016.08.006

CHAN, H. C. Y. (2015). Internet of Things Business Models. Journal of Service Science and Management, 8(4), 552-568. https://doi.org/10.4236/jssm.2015.84056 
CHEW, R. et al. (2013). Big Data, Impactos e

Benefícios. Isaca. Recuperado de http://www.isaca. org/Journal/Pages/

CÔRTE-REAL, N., OLIVEIRA, T., \& RUIVO, P. (2016). Assessing business value of Big Data Analytics in European firms. Journal of Business Research, 70, 379-390. https://doi.org/10.1016/j. jbusres.2016.08.011

COSTA, H. R. N. (2006). Aplicaşão de técnicas de inteligência artificial em processos de fabricação de vidro. Universidade de São Paulo - USP.

CRESPO, A. A. (2010). Estatistica Fácil (1 a ed). São Paulo: Saraiva.

DI STEFANO, G., PETERAF, M., \& VERONA, G. (2014). The Organizational Drivetrain: A Road To Integration of Dynamic Capabilities Research. Academy of Management Perspectives, 28(4), 307-327. https://doi.org/10.5465/amp.2013.0100

DIJKMAN, R. M., SPRENKELS, B., PEETERS, T., \& JANSSEN, A. (2015). Business models for the Internet of Things. International Journal of Information Management, 35(6), 672-678. https://doi. org/10.1016/j.ijinfomgt.2015.07.008

DINH, T., KIM, Y., \& LEE, H. (2017). A LocationBased Interactive Model of Internet of Things and Cloud (IoT-Cloud) for Mobile Cloud Computing Applications. Sensors, 17(3), 489. https://doi. org/10.3390/s17030489

DOBRE, C., \& XHAFA, F. (2014). Intelligent services for Big data science. Future Generation Computer Systems, 37, 267-281. https://doi. org/10.1016/j.future.2013.07.014

DRESNER, K., \& STONE, P. (2008). A multiagent approach to autonomous intersection management. Journal of Artificial Intelligence Research, 31, 591-656. https://doi.org/10.1613/jair.2502

EISENHARDT, K. M., \& MARTIN, J. A. (2000). Dynamic capabilities: what are they? Strategic Management Journal, 21(10-11), 1105-1121. https://doi.org/10.1002/10970266(200010/11)21:10/11<1105::AID-

SMJ133>3.0.CO;2-E

EREVELLES, S., FUKAWA, N., \& SWAYNE, L. (2016). Big Data consumer analytics and the transformation of marketing. Journal of Business
Research, 69(2), 897-904. https://doi.org/10.1016/j. jbusres.2015.07.001

FERNANDES, C., FERREIRA, J. J., RAPOSO, M. L., ESTEVÃO, C., PERIS-ORTIZ, M., \& RUEDAARMENGOT, C. (2017). The dynamic capabilities perspective of strategic management: a co-citation analysis. Scientometrics, 529-555. https://doi. org/10.1007/s11192-017-2397-8

FRANCISCO, E. R., KUGLER, J. R., \& LARIEIRA, C. L. (2017). Líderes da Transformação Digital. GVExecutivo, 22-27.

GALEGALE, G. P., SIQUEIRA, E., SOUZA, C. A. de, \& SILVA, C. B. H. (2016). Internet das Coisas aplicada a negócios: Um estudo bibliométrico. Journal of Information Systems and Technology Management, 13(3), 423-438. https://doi.org/10.4301/S180717752016000300004

GALLARDO, E. G. (2009). David J. Teece Dynamic Capabilities and Strategic Management: Organizing for Innovation and Growth, (3), 217218. Recuperado de http://avaxhm.com/ebooks/ business_job/David33Growth.html

GINIUNIENE, J., \& JURKSIENE, L. (2015). Dynamic Capabilities, Innovation and Organizational Learning: Interrelations and Impact on Firm Performance. Procedia - Social and Behavioral Sciences, 213(1997), 985-991. https://doi.org/10.1016/j. sbspro.2015.11.515

GUBBI, J., BUYYA, R., MARUSIC, S., \& PALANISWAMI, M. (2013). Internet of Things (Io'T): A vision, architectural elements, and future directions. Future Generation Computer Systems, 29(7), 1645-1660. https://doi.org/10.1016/j. future.2013.01.010

GUEDES, A. A., ARAÚJO, D. L. A., \& ORNELLAS, R. S. (2012). Capacidades dinâmicas e vantagens competitivas: um estudo em uma construtora com foco no mercado de baixa renda. XV Simpósio de Administração da Produção, Logística e Operações Internacionais, (1999), 17. Recuperado de http://www.simpoi.fgvsp.br/arquivo/2012/artigos/ E2012_T00206_PCN24063.pdf

GUNASEKARAN, A., PAPADOPOULOS, T., DUBEY, R., WAMBA, S. F., CHILDE, S. J., HAZEN, B., \& AKTER, S. (2017). Big data and predictive analytics for supply chain and organizational performance. Journal of Business 
Research, 70, 308-317. https://doi.org/10.1016/j. jbusres.2016.08.004

HART, J. K., \& MARTINEZ, K. (2015). Toward an environmental Internet of Things. Earth and Space Science, 2(5), 194-200. https://doi. org/10.1002/2014EA000044

HELFAT, C. E., FINKELSTEIN, S., MITCHELL, W., Peteraf, M. A., Singh, H., Teece, D. J., \& Winter, S. G. (2007). Dynamic capabilities: Understanding strategic change in organizations (BlackWell). London.

HERMANN, M., PENTEK, T., \& OT'TO, B. (2015). Design Principles for Industrie 4.0 Scenarios: A Literature Review.

HESS, T., BENLIAN, A., MAT'T, C., \& WIESBÖCK, F. (2016). Options for Formulating a Digital Transformation Strategy. MIS Quarterly Executive, 15(2), 123-139.

JU, K.-J., PARK, B., \& KIM, T. (2016). Causal Relationship between Supply Chain Dynamic Capabilities, Technological Innovation, and Operational Performance. Management and Production Engineering Review, 7(4), 6-15. https://doi. org/10.1515/mper-2016-0031

JUNIOR, J. C. da S. F., MAÇADA, A. C. G., BRINKHUES, R. A., \& DOLCI, P. C. (2015). Dimensões de Big Data e o Processo Decisório: Estudos de Casos Múltiplos no Varejo, 1-15.

KANE, G. C., PALMER, D., PHILIPS NGUYEN, A., KIRON, D., \& BUCKLEY, N. (2015). Strategy, Not Technology, Drives Digital Transformation. MIT Sloan Management Review, (57181), 27. https:/ / doi.org/http://www2.deloitte.com/content/ dam/Deloitte/cn/Documents/technology-mediatelecommunications/deloitte-cn-tmt-strategy-nottechnology-drive-digital-transformation-en-150930. pdf

KLASHANOV, F. (2016). Artificial Intelligence and Organizing Decision in Construction. Procedia Engineering, 165, 1016-1020. https://doi. org/10.1016/j.proeng.2016.11.813

KORNIENKO, A. A., KORNIENKO, A. V., FOFANOV, O. B., \& CHUBIK, M. P. (2015). Knowledge in Artificial Intelligence Systems: Searching the Strategies for Application. Procedia Social and Behavioral Sciences, 166, 589-594. https:// doi.org/10.1016/j.sbspro.2014.12.578
LUI, F., TONG, J., MAO, J., BOHN, R., MESSINA, J., BADGET, L., \& LEAF, D. (2011). NIST Cloud Computing Reference Architecture: Recommendations of the National Institute of Standards and Technology. NIST Special Publication 500-292. https://doi.org/500-299

MAÇADA, A. C. G., \& CANARY, V. P. (2014). A Tomada de Decisão no Contexto do Big Data: estudo de caso único. XXXVIII Encontro da ANPAD - EnANPAD, XXXVIII, 1-17.

MAKRIDAKIS, S. (2017). The Forthcoming Artificial Intelligence (AI) Revolution: Its Impact on Society and Firms, 90, 46-60. https://doi. org/10.1016/j.futures.2017.03.006

MALHOTRA, N. K. (2001). Pesquisa de Marketing: Uma orientação aplicada (3 ed.). Porto Alegre: Bookman.

MARSTON, S., Li, Z., BANDYOPADHYAY, S., ZHANG, J., \& GHALSASI, A. (2011). Cloud computing - The business perspective. Decision Support Systems, 51(1), 176-189. https://doi. org/10.1016/j.dss.2010.12.006

MARTILLA, J. A., \& JAMES, J. C. (1977). Importance-Performance Analysis. Journal of Marketing, 41(1), 77. https://doi. org/10.2307/1250495

MATT, C., HESS, T., \& BENLIAN, A. (2015). Digital Transformation Strategies. Business and Information Systems Engineering, 57(5), 339-343. https://doi.org/10.1007/s12599-015-0401-5

MCAFEE, A., \& BRYNJOLFSSON, E. (2012). Big Data : The Management Revolution. Har, (OctOBeR).

MEIRELLES, D. S. e, \& CAMARGO, Á. A. B. (2014). Capacidades Dinâmicas : O Que São e Como Identificá-las? Dynamic Capabilities: What Are They and How to Identify Them ? Revista de Administração Contemporânea, 18(Dezembro), 41-64. https://doi.org/10.1590/1982-7849rac20141289

MELL, P., \& GRANCE, T. (2010). The NIST Definition of Cloud Computing Recommendations of the National Institute of Standards and Technology.

MICHAILOVA, S., \& ZHAN, W. (2015). Dynamic capabilities and innovation in MNC subsidiaries. 
Journal of World Business, 50(3), 576-583. https://doi. org/10.1016/j.jwb.2014.10.001

MUKHERJEE, M., ADHIKARY, I., MONDAL, S., MONDAL, A. K., PUNDIR, M., \& CHOWDARY, V. (2017). A vision of IoT: Applications, challenges, and opportunities with China perspective. Advances in Intelligent Systems and Computing, 479(4), 553-559. https://doi.org/10.1007/978-981-10-1708-7_63

NOBRE, C. A., SAMPAIO, G., BORMA, L. S., CASTILLA-RUBIO, J. C., SILVA, J. S., \& CARDOSO, M. (2016). Land-use and climate change risks in the Amazon and the need of a novel sustainable development paradigm. Proceedings of the National Academy of Sciences of the United States of America, 113(39), 10759-10768. https://doi. org/10.1073/pnas.1605516113

OESTERREICH, T. D., \& TEUTEBERG, F. (2016). Understanding the implications of digitisation and automation in the context of Industry 4.0: A triangulation approach and elements of a research agenda for the construction industry. Computers in Industry, 83, 121-139. https://doi.org/10.1016/j. compind.2016.09.006

PAN, Y. (2016). Heading toward Artificial Intelligence 2.0. Engineering, 2(4), 409-413. https:/ / doi.org/10.1016/J.ENG.2016.04.018

PANIZZON, M., MILAN, G. S., PERIN, M. G., \& SAMPAIO, C. H. (2015). Capacidades Dinâmicas Baseadas Em Conhecimento E Tipos De Inovação: Proposição De Um Framework De Análise. Review of Administration and Innovation - RAI, 12(1), 271. https://doi.org/10.11606/rai.v12i1.100325

PEREIRA, F. A., SOUSA FILHO, J. M., \& LUCIAN, R. (2009). O Processo da Estratégia em Empresas de Tecnologia da Informação: Um Estudo no Porto Digital. IV 3Es, (January), 1-13.

PFOHL, H.-C., YAHSI, B., \& KURNAZ, T. (2015). The Impact of Industry 4.0 on the Supply Chain. Innovations and Strategies for Logistics and Supply Chains, 32-58.

PREUVENEERS, D., \& ILIE-ZUDOR, E. (2017). The intelligent industry of the future: A survey on emerging trends, research challenges and opportunities in Industry 4.0. Journal of Ambient Intelligence and Smart Environments, 9(3), 287-298. https://doi.org/10.3233/AIS-170432
SAKTHIVEL, R., Parthipan, V., \& Dhanasekaran, D. (2016). Big Data Analytics on Smart and Connected Communities Using Internet of Things. International Journal of Pharmacy \& Technology, 8(4), 19590-19601.

SANTOS, U., AMELOT'TI, L. A., \& VILLAR, F. (2012). Adoção de Computação em Nuvem e suas Motivações. Cloud Security Alliance (CSA), 21. Recuperado de https://chapters. cloudsecurityalliance.org/brazil/files/2012/08/ WhitePaper-AdoçãoDeComputaçãoEmNuvemESua sMotivações-Ago_2012-V1.0.pdf

SCHWAB, K. (2016). A Quarta Revolução Industrial (Edipro). São Paulo. Recuperado de http://www. edipro.com.br/produto/a-quarta-revolucaoindustrial/

SILVA, B. A. M. D. (2011). Decisões do Uso da Tecnologia da Informação: um Estudo sobre o Efeito das Capacidades Dinâmicas. Tese de Doutorado.

SINGH, A., \& Hess, T. (2017). How Chief Digital Officers Promote the Digital Transformation of their Companies. MIS Quarterly Executive, 16(1), 1-17.

SIVARAJAH, U., KAMAL, M. M., IRANI, Z., \& WEERAKKODY, V. (2017). Critical analysis of Big Data challenges and analytical methods. Journal of Business Research, 70, 263-286. https://doi. org/10.1016/j.jbusres.2016.08.001

TEECE, D. J. (2007). Explicating Dynamic Capabilities: The Nature and Microfoundations of (Sustainable) Enterprise Performance. Strategic Management Journal, 1319-1350.

TEECE, D. J., PISANO, G., \& SHUEN, A. M. Y. (1997). Dynamic Capabilities and Strategic Management Author ( s ): David J . Teece, Gary Pisano and Amy Shuen Published by: Wiley Stable URL : http://www.jstor.org/stable/3088148 MANAGEMENT, 18(7), 509-533.

TEECE, D., PETERAF, M., \& LEIH, S. (2016). Dynamic Capabilities and Organizational Agility: RISK, UNCERTAINTY, AND STRATEGY IN THE INNOVATION ECONOMY. California Management review, 58(4). https://doi.org/10.1525/ cmr.2016.58.4.13

TONTINI, G., \& THEISS, J. (2005). Estudo sobre a confiabilidade da classificação dos atributos de um serviço pelo modelo Kano de Qualidade Atrativa e Obrigatória. Revista de Administração e Inovação - RAI, 2(1), 34-50. 
VAN KRANENBURG, R., \& ANZELMO, E. (2008). The Internet of Things. 1st Berlin Symposium on Internet and Society, (October).

Recuperado de http://berlinsymposium.org/sites/ berlinsymposium.org/files/paper_iot-new_covertext. pdf\%5Cnpapers2://publication/uuid/0B8930E421BA-4234-A1AB-56877E2CCB74

VENKATRAM, K., \& GEETHA, M. A. (2017). Review on Big Data \&amp; Analytics - Concepts, Philosophy, Process and Applications. Cybernetics and Information Technologies, 17(2), 3-27. https://doi. org/10.1515/cait-2017-0013

VERAS, M. (2012). Cloud Computing: Nova Arquitetura da TI (1 a ed). Rio de Janeiro: Brasport.

VIEIRA, V., PEDROSA, I., \& SOARES, B. H. (2017). Big data \&amp; analytics: An approach using audit experts' interviews. In 2017 12th Iberian Conference on Information Systems and Technologies (CISTI) (p. 1-6). IEEE. https://doi.org/10.23919/ CISTI.2017.7976069

VOGEL, R., \& GÜT'TEL, W. H. (2013). The dynamic capability view in strategic management: A bibliometric review. International Journal of Management Reviews, 15(4). https://doi.org/10.1111/ijmr.12000

WAMBA, S. F., GUNASEKARAN, A., AKTER, S., REN, S. J., DUBEY, R., \& CHILDE, S. J. (2017). Big data analytics and firm performance: Effects of dynamic capabilities. Journal of Business Research, 70, 356-365. https://doi.org/10.1016/j. jbusres.2016.08.009

WANG, C. L., \& AHMED, P. K. (2007). Dynamic capabilities: A review and research agenda.

International Journal of Management Reviews, 9(1), 31-51. https://doi.org/10.1111/j.1468-2370.2007.00201.x

WEILL, Peter, ROSS, W. J. (2006). Governança de TI - Como as empresas com melhor desempenho administram os direitos decisórios de TI na busca por resultados superiores.

WINTER, S. G. (2003). Understanding dynamic capabilities. Strategic Management Journal, 24, 991-995.

WOLFERT, S., GE, L., VERDOUW, C., \& BOGAARDT, M. J. (2017). Big Data in Smart Farming? A review. Agricultural Systems, 153, 69-80. https://doi.org/10.1016/j.agsy.2017.01.023
ZHU, C., LEUNG, V. C. M., SHU, L., \& NGAI, E. C. H. (2015). Green Internet of Things for Smart World. IEEE Access, 3, 2151-2162. https://doi. org/10.1109/ACCESS.2015.2497312 